Research article

\title{
Utilization of centrate for the outdoor production of marine microalgae at the pilot-scale in raceway photobioreactors
}

\author{
Gabriel Ivan Romero-Villegas ${ }^{\mathrm{a}, *}$, Marco Fiamengo ${ }^{\mathrm{b}}$, Francisco Gabriel Acién-Fernández ${ }^{\mathrm{a}}$, \\ Emilio Molina-Grima ${ }^{\text {a }}$ \\ a Departamento de Ingeniería Química, Universidad de Almería, Ctra. Sacramento, s/n, 04120 La Cañada de San Urbano Almería, Spain \\ ${ }^{\mathrm{b}}$ Dipartimento di Scienze della vita e biotecnologie, Università degli Studi di Ferrara, Via Savonarola, 9, 44121 Ferrara FE, Italy
}

\section{A R T I C L E I N F O}

\section{Keywords:}

Marine microalgae

Centrate from anaerobic digestion of activated

sludge

Flue gases

Nitrogen removal

Phosphorus removal

Carbon removal

Outdoor raceway photobioreactors

\begin{abstract}
A B S T R A C T
In this study, the outdoor production of marine microalgae in raceway photobioreactors was investigated, modifying the centrate percentage in the culture medium (20,30, 40 and 50\%) and using two different dilution rates $\left(0.2\right.$ day $^{-1}$ and 0.3 day $\left.^{-1}\right)$. The data obtained showed that microalgae are capable of producing biomass in addition to recovering the nutrients contained in the centrate. The best results for biomass productivity and light efficiency were obtained when the centrate was set at $20 \%$ with a dilution rate of 0.3 day $^{-1}$. The biomass productivity was $32.42 \mathrm{~g} \mathrm{~m}^{-2}$. $\mathrm{day}^{-1}$ while the photosynthetic efficiency was $0.74 \mathrm{~g}_{\text {biomass }} \cdot \mathrm{E}^{-1}(3.66 \%)$. Regarding the nutrients, nitrogen (the majority being in the form of ammonium $\left[\mathrm{NH}_{4}{ }^{+}\right]$) and phosphorus were only fixed into biomass when optimal conditions were set; if this was not the case, they were lost to stripping or precipitation. The maximal nutrient removal capacities under the optimal conditions were $28.72 \mathrm{mg}_{\mathrm{N}} \cdot \mathrm{l}^{-1} \cdot \mathrm{day}^{-1}$ and $3.99 \mathrm{mg}_{\mathrm{P}} \cdot \mathrm{l}^{-1} \cdot \mathrm{day}^{-1}$. Population changes were determined by the dilution rate set whilst the centrate percentage had little effect. Four strains were present in the culture, Nannochloropsis $g$. being the main one. Biochemical changes did not vary greatly between the conditions set for the culture, with a composition rich in proteins and carbohydrates being observed. One can conclude that to produce marine microalgal biomass for a range of potential commodities such as feed, biofertilizers and biofuels, it is possible to use centrate from anaerobic digestion as the sole nutrient source, as a way of reducing costs.
\end{abstract}

\section{Introduction}

Microalgal biomass has been used over the centuries for a variety of commercial purposes - as an energy source, in food and feed, and in chemical industry management (Ruiz et al., 2016). Not only can it be used to produce biofertilizers, which are in high demand in intensive agriculture, but also for other crops such as cereals and fruit tree crops. This is because microalgae biomass contains plant growth promoters and biopesticides (which increase the productivity of plants and crops, even in small amounts), minimizing the use of chemicals that prevent disease, and reducing the amount of fertilizers required by the crops, thus indirectly enhancing agricultural sustainability.

However, microalgae cultivation requires several major nutrients such as nitrogen, phosphorus and carbon. These elements represent up to $7 \%, 1 \%$ and $50 \%$ of microalgal dry weight, respectively. Nitrogen and phosphorus are supplied as fertilizers whereas carbon is mostly supplemented by $\mathrm{CO}_{2}$; around $1.83 \mathrm{~kg}_{\mathrm{CO} 2} \cdot \mathrm{kg}_{\text {dry-biomass }}{ }^{-1}$ being necessary. In addition, $\mathrm{CO}_{2}$ availability depends on the air-sparger and sump depths, pH and alkalinity, etc. (Posadas et al., 2015), the fixation of which is less than $10 \%$ (Slade and Bauen, 2013) in raceway photobioreactors (PBRs). Moreover, the use of freshwater along with artificial fertilizers increases the biomass production cost above $5.0 € \mathrm{~kg}^{-1}$.

Urban wastewaters contain elevated levels of nitrogen (mainly in the form of ammonium), phosphorus and carbon (both organic and inorganic carbon), which can replace mineral fertilizers in providing microalgae nutrition. However, the use of centrate might limit marine microalgae growth because urban wastewater is mainly freshwater. Nevertheless, various studies have shown that wastewater can be used for marine microalgae growth (Craggs et al., 1997; Jiang et al., 2011), avoiding freshwater wastage. In addition, using flue gases that contain $10-15 \%(\mathrm{v} / \mathrm{v}) \mathrm{CO}_{2}$ may provide the carbon necessary for microalgal cultivation. The carbon content of wastewaters allows us to estimate that approximately one ton of microalgae biomass produced during wastewater treatment reduces green-house-gas $\mathrm{CO}_{2}$ by the equivalent of one ton, compared to conventional wastewater treatment processes; as well as reducing fertilizer use and producing other potential co-

\footnotetext{
* Corresponding author.

E-mail address: gabrielivrovi@gmail.com (G.I. Romero-Villegas).
} 
Table 1

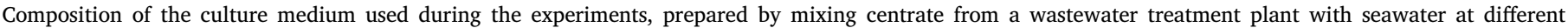
percentages. Concentration expressed as $\mathrm{mg} \cdot \mathrm{l}^{-1}$. In parenthesis, the final phosphorus concentration when adding phosphorus to achieve an $\mathrm{N}$ : $\mathrm{P}$ ratio of 5 .

\begin{tabular}{|c|c|c|c|c|c|}
\hline & $\begin{array}{l}\text { Centrate } \\
100 \%\end{array}$ & $\begin{array}{l}\text { Centrate } \\
50 \%\end{array}$ & $\begin{array}{l}\text { Centrate } \\
40 \%\end{array}$ & $\begin{array}{l}\text { Centrate } \\
30 \%\end{array}$ & $\begin{array}{l}\text { Centrate } \\
20 \%\end{array}$ \\
\hline $\mathrm{pH}$ & 8.19 & 8.05 & 7.35 & 7.65 & 7.40 \\
\hline Bicarbonates & $1830 \pm 742$ & $8500 \pm 371$ & $9834 \pm 296$ & $11168 \pm 244$ & $12502 \pm 148$ \\
\hline Chlorides & $525 \pm 124$ & $10437 \pm 62$ & $12420 \pm 49$ & $14402 \pm 41$ & $16385 \pm 25$ \\
\hline TOC & $35.25 \pm 0.9$ & $17.61 \pm 0.4$ & $16.4 \pm 0.34$ & $11.63 \pm 0.7$ & $7.78 \pm 0.34$ \\
\hline Carbonates & $70 \pm 121$ & $742 \pm 60$ & $877 \pm 48$ & $1011 \pm 40$ & $1146 \pm 24$ \\
\hline Sodium & $252 \pm 74$ & $5815 \pm 37$ & $6927 \pm 30$ & $8040 \pm 24$ & $9152 \pm 15$ \\
\hline Ammonium & $732 \pm 234$ & $366 \pm 117$ & $293 \pm 94$ & $219 \pm 77$ & $146 \pm 47$ \\
\hline Calcium & $133.0 \pm 18$ & $284 \pm 9$ & $315 \pm 7$ & $345 \pm 6$ & $375 \pm 4$ \\
\hline Potassium & $99.6 \pm 5.0$ & $260.7 \pm 2.5$ & $292 \pm 2$ & $325 \pm 2$ & $357 \pm 2$ \\
\hline Magnesium & $88.0 \pm 1.0$ & $728.0 \pm 0.5$ & $856 \pm 2$ & $984 \pm 2$ & $1112 \pm 2$ \\
\hline Sulphates & $38.5 \pm 7.3$ & $1453.0 \pm 3.6$ & $1735 \pm 3$ & $2018 \pm 2$ & $2301 \pm 2$ \\
\hline Phosphorus & $14.1 \pm 3.9(146.1 \pm 4.1)$ & $7.0 \pm 1.9(73.2 \pm 3.5)$ & $5.6 \pm 1.5(58.6 \pm 3.1)$ & $4.36 \pm 1.2(48.2 \pm 2.3)$ & $4.2 \pm 0.8(43.8 \pm 1.3)$ \\
\hline Boron (B) & $0.28 \pm 0.21$ & $0.14 \pm 0.11$ & $0.11 \pm 0.08$ & $0.08 \pm 0.07$ & $0.06 \pm 0.04$ \\
\hline Zinc (Zn) & $0.10 \pm 0.07$ & $0.05 \pm 0.04$ & $0.04 \pm 0.03$ & $0.03 \pm 0.02$ & $0.02 \pm 0.01$ \\
\hline Iron $(\mathrm{Fe})$ & $0.04 \pm 0.01$ & $0.02 \pm 0.01$ & $0.02 \pm 0.01$ & $0.01 \pm 0.01$ & $0.01 \pm 0.01$ \\
\hline Manganese (Mn) & $0.02 \pm 0.01$ & $0.01 \pm 0.01$ & $0.01 \pm 0.01$ & $0.01 \pm 0.01$ & $0.00 \pm 0.01$ \\
\hline Nitrates & $6.55 \pm 6.55$ & $3.28 \pm 3.28$ & $2.62 \pm 2.60$ & $2.0 \pm 2.2$ & $1.3 \pm 1.3$ \\
\hline Copper $(\mathrm{Cu})$ & $0.08 \pm 0.14$ & $0.04 \pm 0.07$ & $0.03 \pm 0.06$ & $0.02 \pm 0.05$ & $0.02 \pm 0.03$ \\
\hline
\end{tabular}

products for agriculture (Van Harmelen and Oonk, 2006). In addition, using wastewater (which is rich in the main compounds necessary for microalgal growth, especially carbon, nitrogen and phosphorus) as the only source of nutrients can reduce biomass production costs by $17 \%$. Furthermore, this microalgal production system consumes $24 \%$ less energy than conventional wastewater systems and it is possible to recover up to $90 \%$ of the nutrients (C, N and P) from wastewater effluents (Acién et al., 2014). When utilising sewage and flue gases in open reactors, the production cost is reduced by one order of magnitude $(<0.5$ $€ \cdot \mathrm{kg}^{-1}$ ) (Acién et al., 2012; Norsker et al., 2011). Therefore, the utilization of an integrated system (wastewater, seawater and flue gases) can be a real option for industrial microalgal production because the production cost is reduced to $<0.5 € \cdot \mathrm{kg}^{-1}$ (Acién et al., 2014; Yang et al., 2011). Additionally, by using low-cost "ready-to-use" raceway PBRs, which are cheaper than closed PBRs (Chisti, 2008), the biomass production cost can be reduced even further; this is because they are easier to clean and require significantly less power consumption for moving and mixing the culture (Ugwu et al., 2008), It is worth noting that using wastewater and natural seawater not only reduces the microalgal production cost, the waste of fresh water and the cost of inorganic fertilizers, but also increases the sustainability and social acceptance of microalgal-based products. Furthermore, with the constant increase in food demand and the incessant damage to the environment caused by excessive chemical fertilizer use to improve crop yields, micro-algae-based products are a key element in using natural products of biological origin to achieve sustainable agriculture. These bioproducts are totally environmentally friendly and non-toxic to plants, animals and final consumers. For this reason, they are considered promising products for day-to-day use in agriculture as there are no toxicity or ecotoxicity problems; they are also safe from the operational standpoint.

Our research studied the performance of the continuous production of marine microalgae biomass using centrate as the nutrient source in natural sea water. Experiments were carried out in summer, using four centrate percentages $(20,30,40$ and $50 \%)$ in sea water and two different dilutions rates $\left(0.2\right.$ and 0.3 day $\left.^{-1}\right)$. System performance was evaluated in terms of dry weight biomass production and nutrient removal capacity. Additionally, an overview was performed of the main strains prevailing inside the cultures as well as the biochemical composition of the produced biomass under study. Our aim was to determine the system's performance and the main factors limiting its efficiency, as a prior step to the industrial development of low-cost marine microalgae biomass production in outdoor raceway PBRs for subsequent use in the commodities markets.

\section{Materials and methods}

\subsection{Microorganism and culture media}

For this study, the marine microalga Nannochloropsis gaditana Lubián CCMP 527 was initially selected due its high growth rate and high productivity under outdoor conditions (San Pedro et al., 2014). Inoculum was grown indoors in 51 glass bottles at a controlled temperature $\left(25^{\circ} \mathrm{C}\right)$ at $200 \mu \mathrm{E} \mathrm{m}^{-2} \cdot \mathrm{s}^{-1}$ under continuous illumination and with aeration at $0.2 \mathrm{v} \cdot \mathrm{v}^{-1} \cdot \mathrm{min}^{-1}$ until the stationary phase. Algal medium (Bionova, Santiago de Compostela, Spain) in seawater was used to cultivate the inoculum. Subsequently, inoculum was transferred to 1001 outdoor bubble columns with algal medium at $\mathrm{pH}$ (8.0), controlled by the on-demand injection of flue gas. Once the stationary phase was reached, the cultures were finally transferred to the raceway photobioreactors, where a mix of natural seawater and centrate at different percentages was used as the culture medium.

The centrate used in this work was taken directly from the wastewater treatment plant (WWTP) of Almería, Spain, operated by Aqualia; more specifically, it was taken after passing through the bed filter used to separate the solids from the liquid fraction of the digestate, after leaving the anaerobic digestion of the activated sludge produced from wastewater treatment. Therefore, this centrate was free of solid particles and rich in ammonium and other compounds. The centrate was brought in 20001 lots. Table 1 shows the average composition of three different centrate lots. The culture medium was prepared daily by supplementing natural seawater with centrate according to the centrate percentage set for each experiment. Additionally, phosphorus was supplied until a nitrogen:phosphorus ratio of 5:1 was reached; this ratio was previously demonstrated as providing optimal culture performance, both indoors (Sepúlveda et al., 2015) and outdoors (Ledda et al., 2015). The seawater used for culture medium preparation was pumped directly from a seawater pump station. No sterilization treatments were performed prior to entering the reactors so as to minimize the production cost.

\subsection{Photobioreactor and culture conditions}

Experiments were performed outdoors from May to September in a set of three raceway photobioreactors oriented north-south. Each PBR was made of $5 \mathrm{~mm}$-thick polyethylene and consisted of two $5.00 \mathrm{~m}$ long 
and $0.60 \mathrm{~m}$ wide channels connected by two $180^{\circ}$ curves with a total surface area of $7.2 \mathrm{~m}^{2}$. A stainless-steel paddlewheel $(0.60 \mathrm{~m}$ diameter) was used for culture circulation at a rate of $0.2 \mathrm{~m} \mathrm{~s}^{-1}$ driven by an electric motor with gear reduction (Ebarba, Barcelona, Spain), the speed was regulated by a frequency inverter (Yaskawa AC Drive V1000, Yaskawa Electric Europe GmbH, Germany). The culture depth in the reactors was set to $0.11 \mathrm{~m}$ since it was reported that both light availability and biomass productivity are enhanced at this depth (San Pedro et al., 2015). Air was constantly injected into the reactor through an air sparger to reduce dissolved oxygen accumulation; the sparger was situated inside a sump located at a $0.85 \mathrm{~m}$ depth upstream of the paddlewheel. The flue gas, containing an average of $10.9 \% \mathrm{CO}_{2}$, was produced on-demand by a diesel-oil boiler connected to a compressor used to store the flue-gas for further utilization. A passive stainless-steel serpentine, connected to the outlet of the boiler, was used for cooling the flue gas. To reduce the soot particulate content in the gas stream, the gas was filtered by three sequential cartridge filters $(1 \mu \mathrm{m})$ before being injected into the cultures. The air flow rate entering each PBR was $0.3 \mathrm{~V} \cdot \mathrm{v}^{-1} \cdot \mathrm{min}^{-1}$ (FR4L72BVBN flow meters, Key Instruments, USA) whereas the flue gas was injected when required at a constant flow rate of $0.05 \mathrm{v} \cdot \mathrm{v}^{-1} \cdot \mathrm{min}^{-1}$ (FR4A41BVBN flow meters, Key Instruments, USA). Dissolved oxygen, $\mathrm{pH}$ and temperature were measured with DO and $\mathrm{pH}$ probes $(5342 \mathrm{pH}$ electrode and 5120 OD electrode, Crison Instruments S.A., Spain) connected to a MM44 control-transmitter unit (Crison Instruments, Spain). The solar radiation received by the facility was measured with a thermoelectric pyranometer connected to an AC420 adapter (LP-02, Geónica S.A., Spain). The data were logged on a PC control unit. The data logging system and the control software (DaqFactory 5.85, Azeotech Inc., USA), which allowed the monitoring and control of the culture parameters, was designed and built by our research group.

This work was carried out during the summer. The experiments were performed in semi-continuous mode, by adding fresh medium daily to the reactors during the $4 \mathrm{~h}$ in the middle of the solar cycle; at the same time harvesting an equal volume of culture. The raceway PBRs were operated at two different dilution rates (D), 0.20 day $^{-1}$ and 0.3 day $^{-1}$. (D represented the culture medium flow rate over the culture volume in the bioreactor; so, depending of the dilution rate used, every day $20 \%$ or $30 \%$ of the culture medium was harvested while adding the same amount of fresh culture medium). The culture medium was prepared directly by the daily mixing of centrate at four different centrate percentages $(20 \%, 30 \%, 40 \%$ and $50 \%)$ with seawater pumped directly from the seawater pump station (i.e. the centrate amount per litre of seawater, given as a fraction based on 100 equal parts). The centrate percentage influences the amount of nutrients provided daily to the reactors whereas the set dilution rate influences microalgae biomass harvesting; thus, the final biomass concentration inside the culture was at steady state. The experiments were performed in the three reactors simultaneously, and in triplicate (the average values from the three reactors were recorded). Other native strains were found in the culture, mainly because the culture medium was not sterilized.

\subsection{Biomass concentration and quantum yield determination}

The biomass concentration was determined daily by measuring absorbance at $750 \mathrm{~nm}$ with a spectrophotometer (DR/4000 UV/Vis Spectrophotometer, HACH, USA). The spectrophotometric measurements were verified by dry weight determinations twice a week. The dry weight biomass concentration $\left(\mathrm{C}_{\mathrm{b}}\right)$ was measured by centrifuging $100 \mathrm{ml}$ of culture for $15 \mathrm{~min}$ at $4500 \mathrm{RPM}$; the sediment was taken and freeze dried in a lyophilizer (LYOQUEST-55 Telstar Technologies, S.L. Spain) for $24 \mathrm{~h}$ and subsequently weighed. To determine the extinction coefficient of the biomass $\left(\mathrm{K}_{\mathrm{a}}\right)$, the average absorbance at wavelengths from 400 to $700 \mathrm{~nm}$ was divided by the biomass concentration $\left(\mathrm{C}_{\mathrm{b}}\right)$ and the cuvette light path $\left(\mathrm{P}_{\text {cuvette }}\right)$ (Equation (1)).
$K_{a}=\frac{A b s}{C_{b} \cdot P_{\text {cuvette }}}$

Volumetric productivity was calculated according to equation (2), multiplying the biomass concentration $\left(\mathrm{C}_{\mathrm{b}}\right)$ by the dilution rate (D).

$P b_{b v o l}=C_{b} \cdot D$

The land areal productivity was calculated according to a previous work (San Pedro et al., 2015), the volume-surface ratio was calculated taking into account the working volume of the reactor and the land surface occupied by it, which included the distance between reactors; the volumetric biomass productivity was divided by the land area, which likewise included the distance between reactors, according to equation (3).

$P b_{\text {area }}=\frac{P b_{\text {vol }}}{\text { Area }}$

\subsection{Light availability and solar efficiency}

The average irradiance (in the photosynthetically active radiation range, PAR) at which cells are exposed inside a culture $\left(I_{a v}\right)$ is a function of irradiance in the absence of cells $\left(\mathrm{I}_{\mathrm{o}}\right)$, the biomass extinction coefficient $\left(\mathrm{K}_{\mathrm{a}}\right)$, the biomass concentration $\left(\mathrm{C}_{\mathrm{b}}\right)$ and the light path inside the reactor (p). It can be approximated using equation (4) (Molina Grima et al., 1996).

$I_{a \nu}=\frac{I_{0}}{\left(K_{a} \cdot p \cdot C_{b}\right)}\left(1-\exp \left(-K_{a} \cdot p \cdot C_{b}\right)\right)$

Quantum yield $\left(\Psi_{\mathrm{E}}\right)$ is defined in microalgal cultures as the amount of biomass generated by the unit of radiation (usually a mole of photons) absorbed by the culture. Since this represents the ratio of biomass generation to absorbed photon flux, it can be calculated by equation (5) (Molina Grima et al., 1996), where $\mathrm{Pb}_{\mathrm{vol}}$ stands for the volumetric biomass productivity and $\mathrm{F}_{\mathrm{vol}}$ for the photon flux absorbed in the volume unit. The photon flux absorbed through the reactor volume may be obtained from the $I_{a v}$ on a culture volume basis using equation (6) (Molina Grima et al., 1996):

$\Psi_{E}=\frac{P b_{v o l}}{F_{v o l}}$

$F_{v o l}=I_{a v} \cdot K_{a} \cdot C_{b}$

Photosynthetic efficiency (the maximum efficiency at which photosynthesis can convert solar energy into biomass) was calculated according to equation (7) (Molina Grima et al., 1996), where $\mathrm{Q}_{\mathrm{b}}$ (biomass combustion heat) and $\mathrm{F}_{\mathrm{vol}}$ are given in energy units.

Photosynthetic efficiency $=\frac{P b_{v o l} \cdot Q_{b}}{F_{v o l}}$

\subsection{Nutrient removal capacity and stripping}

Nitrogen, phosphorus and carbon depuration efficiencies $\left(\mathrm{R}_{\mathrm{e}}\right)$ and removal capacities $\left(R_{c}\right)$ were calculated according to equations (8) and (9):

$R_{e}=\frac{C_{0}-C}{C_{0}} \cdot 100$

$R_{c}=\left(C_{0}-C\right) \cdot D$

where $C_{0}$ is the element concentration at the culture inlet, $C$ is the element concentration at the culture outlet and $\mathrm{D}$ is the dilution rate at which the experiment was set.

Carbon and phosphorus losses were calculated according to equation (10): 


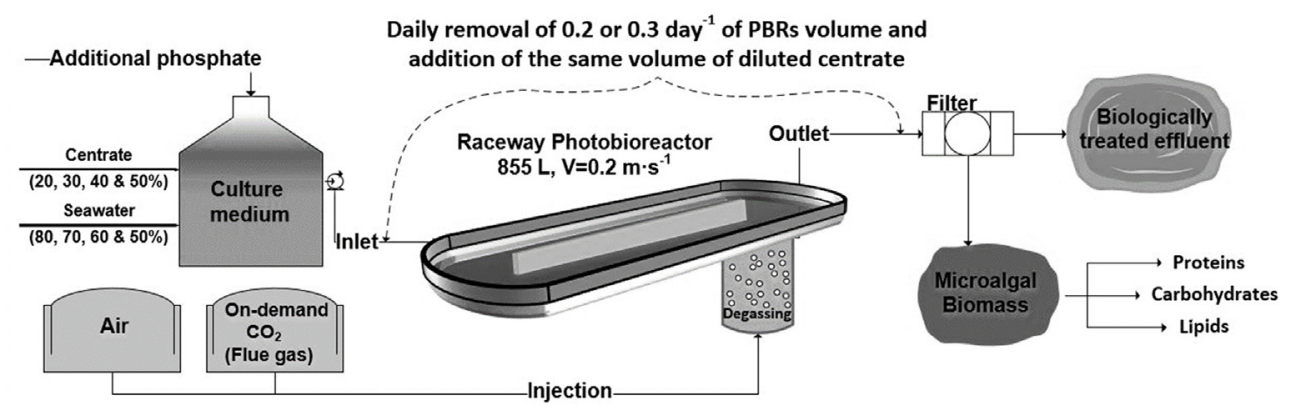

Fig. 1. Process schematic of microalgal biomass production using centrate as the culture medium in the outdoor raceway photobioreactors used in this experiment.

$\% C_{\text {loses }}=\left(1-\frac{\left(P_{b} \cdot \% \mathrm{C}_{\text {biomass }} \cdot 1000\right)+(\mathrm{C} \cdot D)}{C_{0}}\right) * 100$

Nitrogen stripping is a physical separation where nitrogen is removed from a liquid stream by a vapour stream (Henley et al., 2011); this was measured according to equation (11):

$\% N_{\text {Stripping }}=\left(1-\frac{\left(P_{b} \cdot \% \mathrm{~N}_{\text {biomass }} \cdot 1000\right)+\left(N_{\text {outlet }} \cdot D\right)}{N_{\text {inlet }}}\right) * 100$

\subsection{Analytical methods}

To analyse the culture medium and the supernatant, we used the standard official methods approved by the Spanish Ministry of Agriculture (Ministerio de Agricultura, 1998). Phosphate was measured by visible spectrophotometry through the phospho-vanado-molybdate complex (APAT-IRSA/CNR, 2003). Nitrates were quantified using a spectrophotometer between 220 and $275 \mathrm{~nm}$ (APAT-IRSA/CNR, 2003). Ammonium was measured by the Nessler reaction method (APATIRSA/CNR, 2003). Total Inorganic Carbon (TIC), Total Organic Carbon (TOC) and Total Carbon (TC) were measured by direct injection of previously filtered samples into a Shimadzu-5050A TOC analyser provided with an NDIR detector and calibrated with standard solutions of potassium phthalate.

Microalgal population analysis for counting and taxonomic identification were performed using the Utermöhl method; briefly, the microalgae were preserved in formaldehyde to maintain sample viability, they were then placed in a cylindrical sedimentation chamber where they were counted and identified by inverted microscopy (Edler and Elbrächter, 2010). With regard to the biomass, freeze-dried biomass from each steady state was analyzed. Lipids were determined gravimetrically from an extract obtained with chloroform:methanol (2:1) (v/v) (Raven, 1979). The protein content was determined using the modified Lowry method (López González et al., 2010). Fatty acids were determined by gas chromatography (Rodríguez-Ruiz et al., 1998).

\section{Results and discussion}

\subsection{Culture medium composition}

The assays were carried out in a set of three raceway photobioreactors by modifying the centrate percentage in the culture medium and the set dilution rate. The optimal conditions for the semi-continuous outdoor production of marine microalgae in raceway photobioreactors were determined using a mix of centrate and natural seawater at two dilution rates $\left(0.2 \mathrm{day}^{-1}\right.$ and $\left.0.3 \mathrm{day}^{-1}\right)$ and four different centrate percentages $(20 \%, 30 \%, 40 \%$ and $50 \%)$ as the sole nutrient source. The culture medium was prepared daily by mixing centrate and natural seawater. In addition, phosphorus was added to balance the nitrogen:phosphorus ratio (N:P; 5:1), Daily fresh culture medium was added to the reactors during the $4 \mathrm{~h}$ in the middle of the solar cycle, at the same time harvesting an equal volume of culture. These assays were carried out in the summer, with no cooling system, at temperatures up to $39^{\circ} \mathrm{C}$.

The centrate compositional analysis used in this work is shown in Table 1; it indicates a high content of bicarbonates $\left(1830 \mathrm{mgl}^{-1}\right)$, chlorides $\left(525 \mathrm{mg} \mathrm{l}^{-1}\right.$ ) and ammonium $\left(700 \mathrm{mg} \mathrm{l}^{-1}\right.$ )(which is the main nitrogen source) whereas compounds like phosphorus $\left(11.5 \mathrm{mgl}^{-1}\right)$ and nitrate $\left(4.4 \mathrm{mg}^{-1}\right)$ were limited; other important elements for microalgal growth (iron, sodium, calcium and potassium etc.) were also present in the centrate. If one considers that the microalgae biomass composition is $50 \% \mathrm{C}, 7 \% \mathrm{~N}$, and $1 \% \mathrm{P}$, then to produce $1.0 \mathrm{~g}$ of microalgal biomass, $2500 \mathrm{mg}$ of $\mathrm{HCO}_{3}{ }^{-}, 90 \mathrm{mg}$ of $\mathrm{NH}_{4}{ }^{+}$(or $310 \mathrm{mg}$ of $\mathrm{NO}_{3}{ }^{-}$) and $10 \mathrm{mg}$ of $\mathrm{P}$ are required. The centrate's nutrient content surpasses the ammonium demanded for the efficient uptake of phosphorus and bicarbonates. Nevertheless, it has been demonstrated that using this culture medium with an imbalance of these two compounds causes deficient microalgae growth, both for indoor (Sepúlveda et al., 2015) and outdoor cultures (Ledda et al., 2015).

The elemental composition, after phosphorus was added, showed a $\mathrm{C} / \mathrm{N} / \mathrm{P}$ average of $100 / 128 / 19$ in the culture medium and 100/21/2 for the biomass, which denotes a carbon deficit in the culture medium, or an excess of nitrogen and phosphorus. This is important as it has been observed that a low phosphorus content in the centrate (before adding) limits microalgal growth (Sepúlveda et al., 2015). Conversely, a considerable increase in cell concentration was observed when a balanced N:P ratio was set (5:1) (Ledda et al., 2015; Sepúlveda et al., 2015); the biomass concentration being equivalent to those in cultures where commercial Algal medium was used (San Pedro et al., 2015). Despite a high carbon content being determined, additional carbon was supplied by on-demand $\mathrm{CO}_{2}$ injection. Fig. 1 shows the schematic diagram of the process in this study.

\subsection{Biomass productivity}

Regarding biomass productivity (Fig. 2), one can observe that a stable steady state was achieved when the centrate percentage was equal to or below $40 \%$ while, above this value, the cultures were washed-out. The results show that, when using centrate and natural seawater, the biomass concentration (Fig. 2A) and biomass productivity (Fig. 2B; 2C) changed according to the different conditions set, decreasing as the percentage of centrate increased in the culture medium. This demonstrates that a centrate increase in the culture medium is harmful for cell growth, which might be because of the high ammonium concentration, reaching values of $146 \mathrm{mgl}^{-1}$ when there was $20 \%$ centrate in the culture medium. It was observed that maximal biomass concentration $\left(0.98 \mathrm{~g}_{\text {biomass }} \mathrm{l}^{-1}\right)$ and biomass productivity $(0.27$ $\mathrm{g}_{\text {biomass }} \mathrm{l}^{-1}$.day ${ }^{-1}$ and $32.42 \mathrm{~g}_{\text {biomass }} \cdot \mathrm{m}^{-2}$. day $^{-1}$ ) were achieved with $20 \%$ centrate and a dilution rate of 0.2 day $^{-1}$ and 0.3 day $^{-1}$, respectively. Nevertheless, when a centrate percentage above $40 \%$ was used, the culture became stressed and was consequently washed out. The maximal values obtained here are based on data obtained by Sepulveda et al. (2015), where the maximal biomass productivity values were 0.27 $\mathrm{g}_{\text {biomass }} \mathrm{l}^{-1} \cdot \mathrm{day}^{-1}$ under indoor conditions, using Nannochloropsis $\mathrm{g}$. 

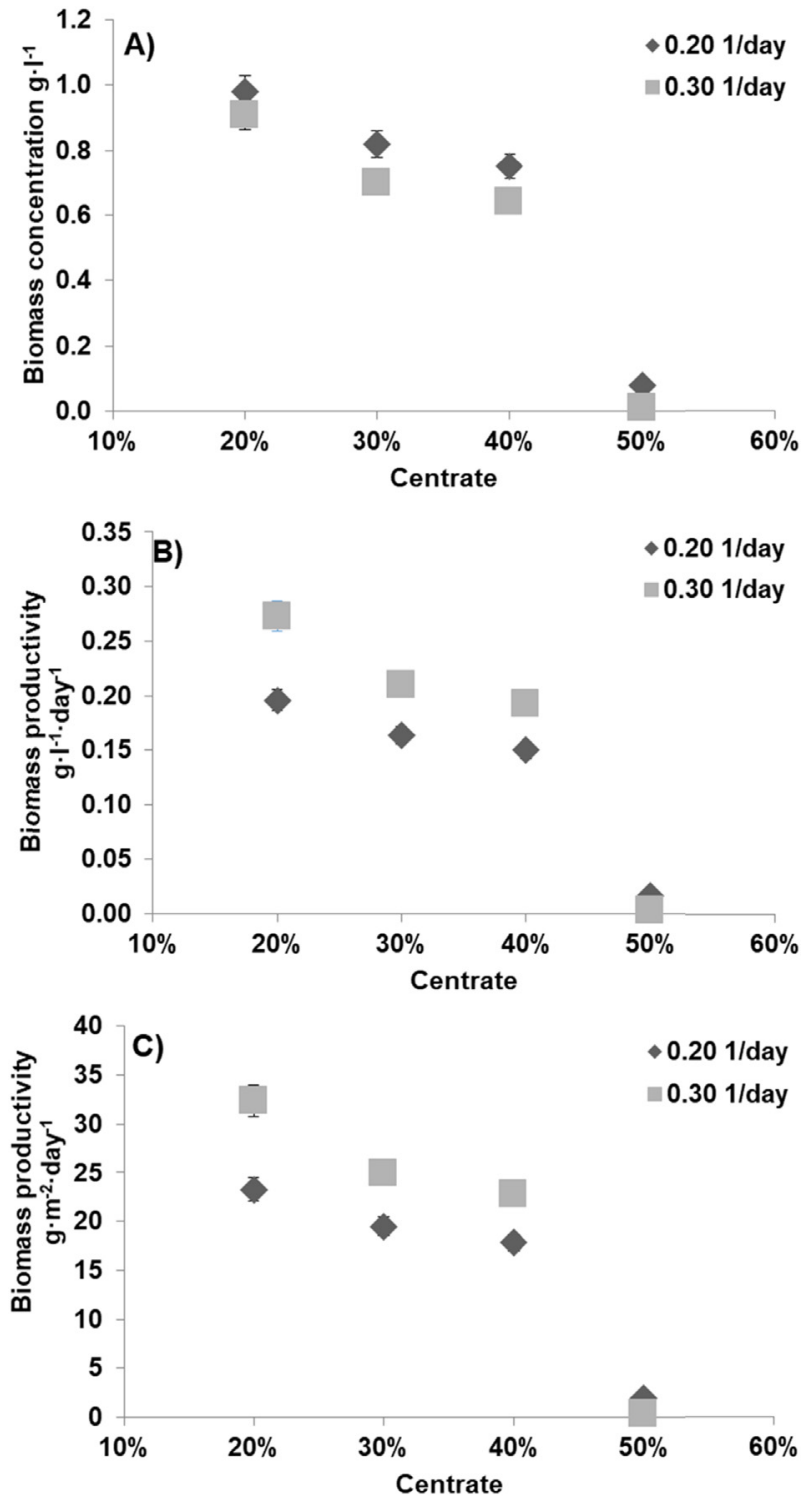

Fig. 2. Influence of the centrate percentage in the culture medium and the imposed dilution rate on the biomass concentration and productivity in outdoor raceway photobioreactors. A) Biomass concentration, B) Volumetric biomass productivity, C) Land areal biomass productivity. Mean + S.D. values are shown for the independent experiments performed in triplicate $(\mathrm{P}<0.05)$.

with $20-40 \%$ centrate. For outdoor conditions, maximal values of 0.09 $\mathrm{g}_{\text {biomass }} \mathrm{l}^{-1}$. day ${ }^{-1}$ with a commercial algal medium (San Pedro et al., 2015) and 0.07 gbiomass $^{-1} \cdot$ day $^{-1}$ with a similar mix of centrate and seawater (Ledda et al., 2015) were observed. The data obtained in analogous studies in tubular (Romero Villegas et al., 2017) and flatpanels (Romero-Villegas et al., 2018) PBRs, using the same culture medium under the same conditions, demonstrated that raceway PBRs had the lowest biomass productivity efficiency, not dissimilar to data obtained from flat-panel PBRs $\left(1.16 \mathrm{~g}_{\text {biomass }} \mathrm{l}^{-1}\right)$ whereas values obtained with tubular PBRs doubled the biomass concentration $(2.02$ g $_{\text {biomass }} \cdot 1^{-1}$ ). Nevertheless, the maximum land areal biomass productivity achieved in tubular PBRs was only $15.6 \mathrm{~g}_{\text {biomass }} \cdot \mathrm{m}^{-2}$. $\mathrm{day}^{-1}$, (Romero Villegas et al., 2017), evidencing that raceways PBRs are suitable for microalgal biomass production.

\subsection{Microalgae population strains}

The use of alternative nutrient sources such as wastewater (in this case centrate), increases both the sustainability and the profitability of the process because it contains an excess of required nutrients (nitrogen, phosphorus and carbon). Nevertheless, the process involves a series of "issues" owing to its contaminating effect, leading some authors to suggest that the centrate should be sterilized before use (Ledda et al., 2016); this is because it contains an extra load of other microorganisms derived from the non-sterilization of the culture medium.

One of the aims of this current research is to demonstrate that the use of centrate can reduce the cost of the microalgal biomass obtained; i.e. that any option for "improving" the nutrient source translates into an increased production cost. Yet the growth of contaminant species is an important issue. The microalgal population analysis (Fig. 3) and taxonomic studies demonstrated that there were four strains in the culture, Pseudoanabaena sp., Nannochloropsis g., Halamphora sp. and Geitlerinema sp., which varied in population size depending on the operational conditions set in each experiment. With regard to the relative population, it was observed that this could be modified by the centrate percentage in the culture medium (Fig. 3A). Geitlerinema sp. was the predominant strain when the centrate percentage was low, while Halamphora sp.'s relative population was greater when centrate increased to $40 \%$. On the other hand, the predominant species in terms of dilution rate changes (Fig. 3B) was Nannochloropsis $g$. for both dilution rates. Results obtained in analogous works demonstrated that microalgal population changes depend on the characteristics of the particular PBR. While tubular PBRs showed 5 different species (Romero Villegas et al., 2017), flat-panels PBRs exhibited only two strains (Nannochloropsis g. and Geitlerinema sp.) (Romero-Villegas et al., 2018), whereas previous studies showed that monocultures of Nannochloropsis g. (Ledda et al., 2015) and Scenedesmus sp. (Morales-Amaral et al., 2015) could be obtained using wastewater in raceway PBRs. In contrast, some works state that the production of native microalgae consortia from wastewater is feasible as this facilitates the use of centrate as the culture medium's nutrient source and increases the culture's ability to produce biomass - it has been shown that each microalgae strain plays a different role in tackling real wastewater treatment issues; e.g. Chlorella sp. is used for the removal of lead (II) ions, nitrogen and phosphate, and cyanide (Aksu and Kutsal, 1991), Scenedesmus sp. is used to remove cadmium and copper (Terry and Stone, 2002), while Spirulina sp. (Bagus Pradana et al., 2014) and Dunaliella salina (Imani et al., 2011) are used for the bio-absorption of heavy metals, etc. Thus, microalgal consortia can be designed that permit the recovery of specific nutrients based on the particular characteristics of each wastewater type.

\subsection{Biochemical composition}

The biochemical quality of the obtained biomass is the most relevant and important issue as it is necessary to determine if the product can be used or not, as well as determining whether it is for human or non-human use (Ruiz et al., 2016). There have been several studies regarding the use of microalgal biomass for biofuel production although microalgal biomass must be considered for agricultural use as well as for added-value bio-stimulant/biopesticide products and low-value biofertilizer products - the estimated global market for bio-stimulants in 2012 was $\$ 3.4$ billion, $\$ 2.4$ billion for biopesticides and $\$ 440 \mathrm{M}$ for biofertilizers (Transparency Market Research, 2014). Furthermore, the market price for bio-stimulants/biopesticides and biofertilizers ranges from 9 to $24 € \cdot 1^{-1}$ and from 1 to $10 € \cdot 1^{-1}$, respectively (Soley Biotechnology Institute, 2014). For this reason, biochemical analyses of the obtained biomass were performed (Fig. 4). The data show that the predominant biomass contents were carbohydrates (21\%-52\%) (Fig. 4A) and proteins (up to 52\%) (Fig. 4B). The lipid content was very stable with an average value of $23 \%$ (all values were below 29\%) (Fig. 4C). This is comparable to biochemical compositions for different microalgae species cultivated in inorganic culture medium (Table 2). One of the most recent publications on the estimated values of the 

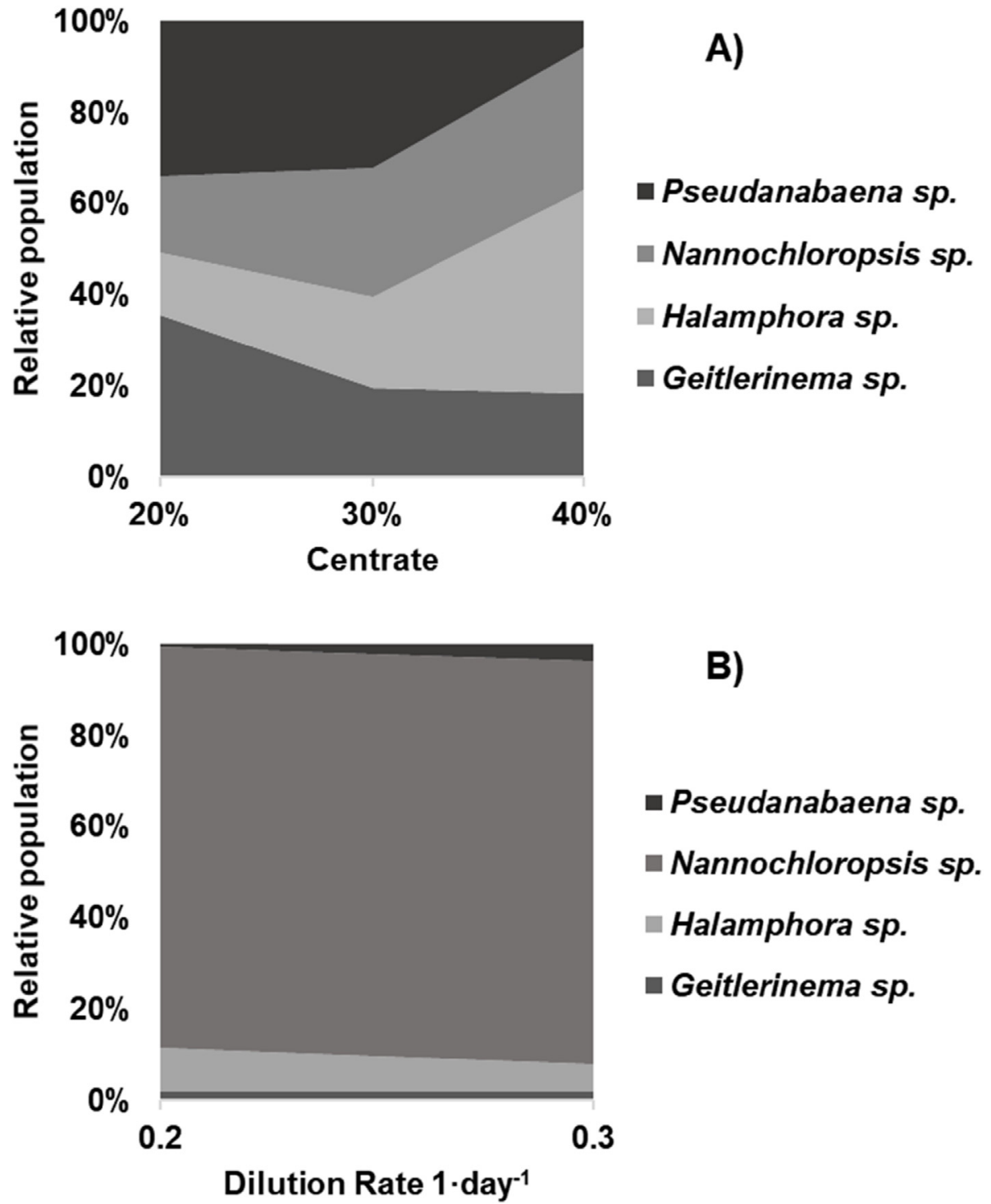

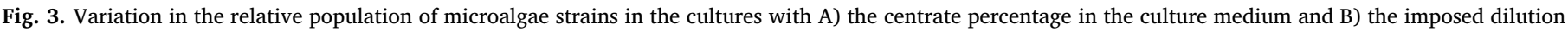
rate in the outdoor raceway photobioreactors. Mean + S.D. values are shown for the independent experiments performed in triplicate $(\mathrm{P}<0.05)$.

different sub-products in the microalgal biomass market (Ruiz et al., 2016) shows that the price for carbohydrates, proteins and lipids are around $0.3 € \cdot \mathrm{kg}^{-1}, 1.0 € \cdot \mathrm{kg}^{-1}$ and $0.6 € \mathrm{~kg}^{-1}$, respectively. Therefore, it can be estimated that the microalgal biomass obtained in this study could reach a maximum value of $0.74 € \cdot \mathrm{kg}^{-1}$ using $30 \%$ centrate and a dilution rate of 0.2 day $^{-1}$. This is higher than the biomass prices obtained for tubular PBRs in analogous works $\left(0.67 € \cdot \mathrm{kg}^{-1}\right.$ ) (Romero Villegas et al., 2017). Moreover, the biomass analysis leads us to conclude that the most suitable markets for this product are those for animal feed or aquaculture. Nonetheless, more analyses must be carried out before accurately ascertaining the reliability of any final application.

\subsection{Light-use efficiency}

To assess the performance of the light-use conditions set in the cultures, we evaluated the average irradiance within the culture, the quantum yield and the photosynthetic efficiency (Fig. 5). Based on the average irradiance (the average irradiance the cells were exposed to within the cultures as a function of the culture medium and the photobioreactor used), Fig. 5A shows values from 20 to $88 \mu \mathrm{E} \mathrm{m}^{-2} \cdot \mathrm{s}^{-1}$ using $20 \%-40 \%$ centrate. However, when $50 \%$ centrate was used, the culture became washed out, evidencing the damage caused by the higher ammonium concentration. The data confirm that culture efficiency reduced relative to each centrate percentage increase in the culture medium, as more light was needed to maintain the growth rate. Regarding the quantum yield (Fig. 5B), this variable also allows us to evaluate the differences in efficiency between treatments, whereas the photosynthetic efficiency (Fig. 5C) lets us determine the energy performance fixed by the action of photosynthesis as a function of the light received on the PBR surface - under outdoor conditions, the maximal hypothetical PAR radiation was 5-6\%. We were therefore able to determine both the quantum yield and the photosynthetic efficiency with the data showing that both presented a decreasing trend when centrate increased in the culture medium - the maximal quantum yield value was $0.74 \mathrm{~g}_{\text {biomass }} \cdot \mathrm{E}^{-1}$ and the photosynthetic efficiency was $3.66 \%$ when the dilution rate was set at $0.3 \mathrm{day}^{-1}$. Nevertheless, the values obtained at a 0.2 day $^{-1}$ dilution rate were more stable, showing an average quantum yield value of $0.44 \mathrm{~g}_{\text {biomass }} \mathrm{E}^{-1}$ and photosynthetic efficiency of $2.19 \%$; however, both dropped to zero when the centrate percentage rose to $50 \%$. Previous studies carried out in the same facilities showed that Nannochloropsis g. monocultures could achieve maximum values up to $0.27 \mathrm{~g}_{\text {biomass }} \mathrm{E}^{-1}$ in algal medium (San Pedro et al., 2015) whereas the use of $20 \%$ centrate in seawater (as the culture 

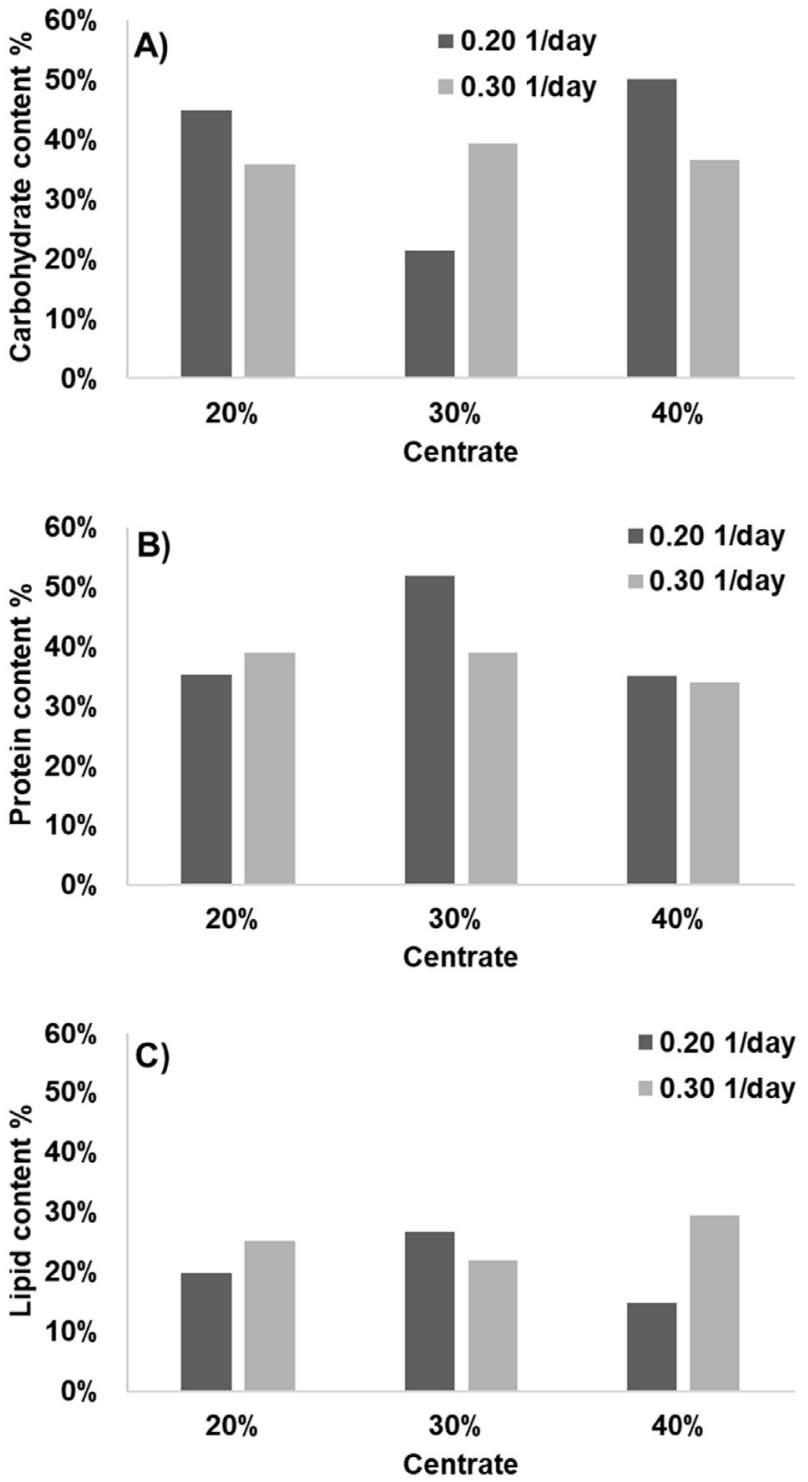

Fig. 4. Variation in the A) carbohydrate content, B) protein content and C) lipid content of the microalgae biomass produced as a function of the centrate percentage in the culture medium and the imposed dilution rate in the outdoor raceway photobioreactors. Mean + S.D. values are shown for the independent experiments performed in triplicate $(\mathrm{P}<0.05)$

Table 2

Composition of microalgae biomass in terms of nutritional value: protein, carbohydrates, and lipids (Taken from Maizatul et al. (2017)).

\begin{tabular}{llll}
\hline Microalgae species & Protein & Carbohydrates & Lipids \\
\hline Botryococcus braunii & 40 & 2 & 33 \\
Chlorella sp. & 46.7 & 11.6 & 14.8 \\
C. vulgaris & $51-58$ & $12-17$ & $14-22$ \\
Dunaliella Salina & 57 & 32 & 6 \\
D. bioculata & 49 & 4 & 8 \\
Scenedesmus sp. & 52.3 & 10.06 & 12.2 \\
S. dimorphus & $8-18$ & $21-52$ & $16-40$ \\
S. obliquus & $50-56$ & $10-17$ & $12-14$ \\
Spirulina maxima & $60-71$ & $13-16$ & $6-7$ \\
S. platensis & $42-63$ & $8-14$ & $4-9$ \\
Tetraselmis maculata & 52 & 15 & 3
\end{tabular}

medium) achieved $0.24 \mathrm{~g}_{\text {biomass }} \mathrm{E}^{-1}$ (Ledda et al., 2015). Moreover, efficiencies of up to $5 \%$ have been reported for Scenedesmus sp. in raceway PBRs (Morales-Amaral et al., 2015) and 3.6\% for tubular PBRs
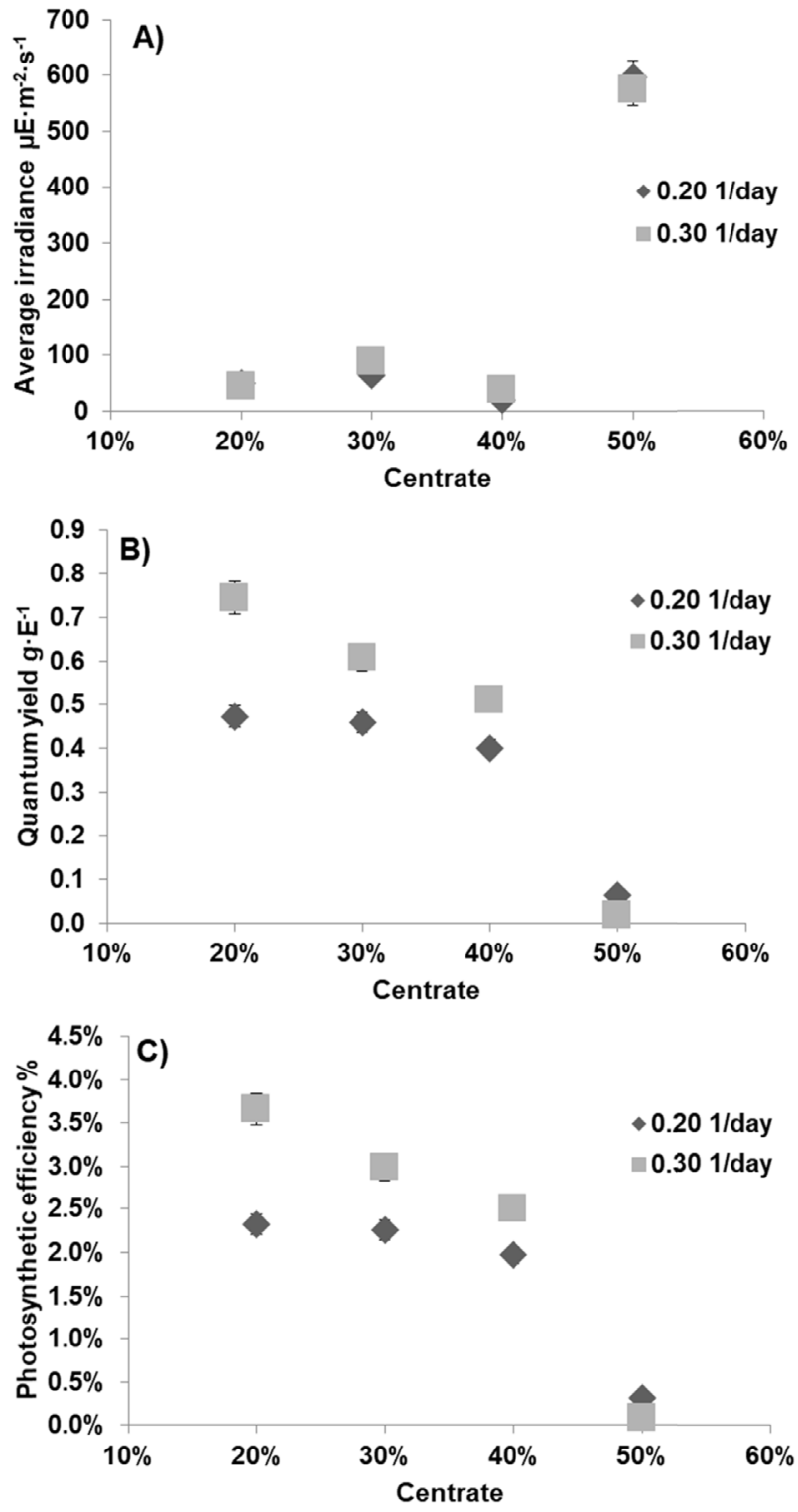

Fig. 5. Influence of the centrate percentage in the culture medium and the imposed dilution rate on the A) Average irradiance, B) Quantum yield and C) Photosynthetic efficiency to which the cells are exposed inside the cultures in the outdoor raceway photobioreactors. Mean + S.D. values are shown for the independent experiments performed in triplicate $(\mathrm{P}<0.05)$.

(Acién et al., 2012). Nevertheless, data obtained in analogous works for tubular $\left(0.54 \mathrm{~g}_{\text {biomass }} \mathrm{E}^{-1}\right)$ PBRs showed lower light-use efficiency with values of $2.67 \%$ and $2.79 \%$ (Romero Villegas et al., 2017), demonstrating that raceway PBRs made the most of the light received.

\subsection{Nutrient removal}

The production of microalgal biomass using centrate as the culture medium not only allows us to obtain biomass, but also removes compounds that can contaminate our aquatic bodies, making the most of the carbon (Fig. 6), nitrogen (Fig. 7A and B) and phosphorus (Fig. 7C and D), which are essential components in microalgal biomass composition, as well as being critical for cell division and intracellular metabolite cycling. The additional advantage of this method is that depuration process costs are reduced because available domestic municipal wastewater can be used as the culture medium for microalgae cultivation while benefitting from bioremediation. For this reason, the 

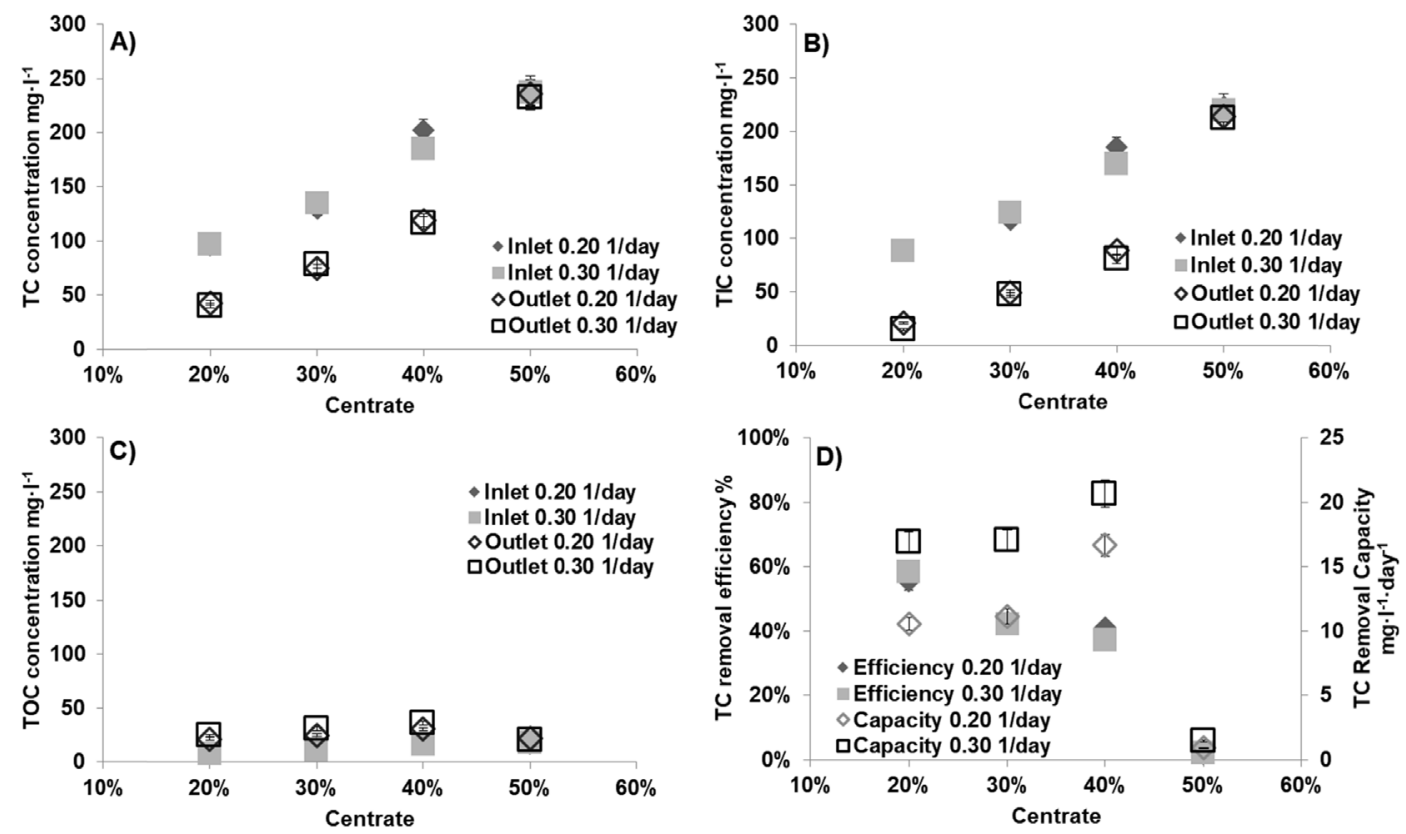

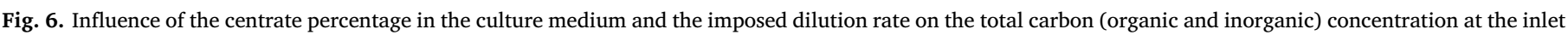

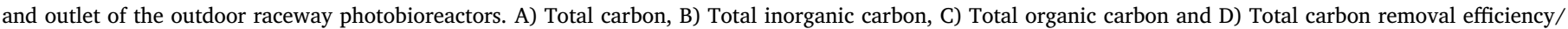
capacity. Mean + S.D. values are shown for the independent experiments performed in triplicate $(\mathrm{P}<0.05)$.

carbon, nitrogen and phosphorus levels were measured. Another aspect of microalgae cultivation is that cultures need $\mathrm{CO}_{2}$ to satisfying their carbon demand. Nevertheless, this demand can be covered by the centrate, which contains elevated levels of carbon (Table 1) while at the same time, reduce the carbon footprint of the wastewater plants. Regarding carbon analysis, the data show that total carbon (TC) at the inlet (Fig. 6A) ranged from $95.35 \mathrm{mg}_{\mathrm{TC}} \mathrm{l}^{-1}$ to $240.81 \mathrm{mg}_{\mathrm{TC}} \mathrm{l}^{-1}$, of which total inorganic carbon (TIC) (Fig. 6B) represented more than $90 \%$, while values of total organic carbon (TOC) (Fig. 6C) ranged from $7.4 \mathrm{mg}_{\mathrm{TOC}} \mathrm{l}^{-1}$ to $18 \mathrm{mg}_{\mathrm{TOC}} \mathrm{l}^{-1}$ - all of them increasing as the centrate level increased in the culture medium. Similar behaviour was observed at the outlet, where the TC remaining in the culture medium increased as the centrate percentage increased $\left(40 \mathrm{mg}_{\mathrm{TC}} \mathrm{l}^{-1}-119 \mathrm{mg}_{\mathrm{TC}} \mathrm{l}^{-1}\right)$, with a maximal removal capacity (Fig. 6D) of up to $20.67 \mathrm{mg}_{\mathrm{TC}} \mathrm{l}^{-1} \cdot$ day $^{-1}$ when $40 \%$ centrate and a dilution rate of 0.3 day $^{-1}$ were used. Nevertheless, maximal depuration efficiency (Fig. 6D) was observed using $20 \%$ centrate and a dilution rate of 0.3 day $^{-1}(58.5 \%, 16.9$ $\mathrm{mg}_{\mathrm{TC}} \mathrm{l}^{-1}$. day $^{-1}$ ). Moreover, despite outlet values showing an important reduction in TC values, it has been shown that a high concentration of carbonates in the culture medium reduces the need for pure $\mathrm{CO}_{2}$ and lowers the biomass production cost from $2.1 \$_{\text {USD }} \cdot \mathrm{kg}_{\text {dry-biomass }}{ }^{-1}$ to 1.0 $\$_{\text {UsD }} \mathrm{kg}_{\text {dry-biomass }}{ }^{-1}$ (Hanifzadeh et al., 2018). Nonetheless, the data
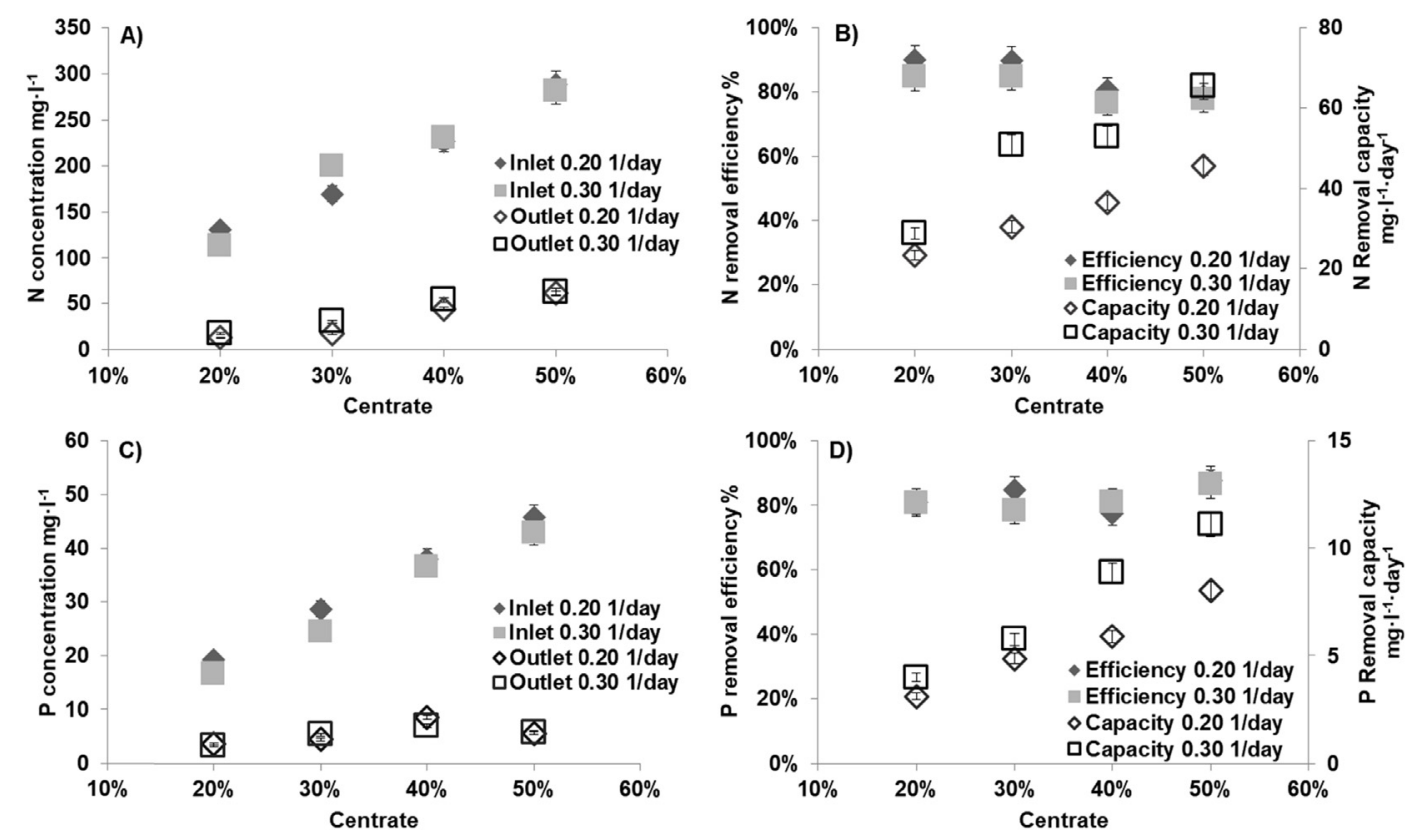

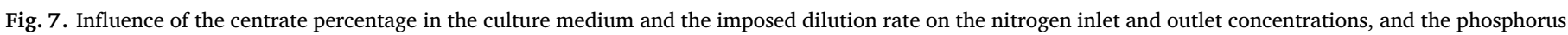

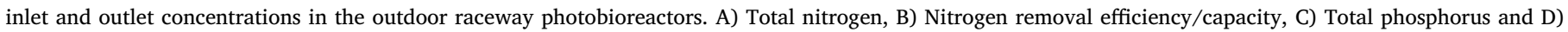
Phosphorus removal efficiency/capacity. Mean + S.D. values are shown for the independent experiments performed in triplicate $(\mathrm{P}<0.05)$. 
showed that the culture needed more carbon than was supplied by the culture medium. Thus, the $\mathrm{CO}_{2}$ used for $\mathrm{pH}$ control also played a role as a carbon source along with the TIC suspended in the medium. Unlike at the inlet, the TIC percentage at the outlet decreased by $38 \%$ with respect to the TOC values, except when $50 \%$ centrate was used (213 $\mathrm{mg}_{\text {TIC }} \mathrm{l}^{-1}$ ); giving similar values to those at the inlet and evidencing that this microalga bloom preferred TIC to TOC for feeding. In addition, the TOC rose significantly to $35.7 \mathrm{mg}_{\mathrm{TOC}} \mathrm{l}^{-1}$, suggesting that the microalgae produced then excreted organic compounds, which consequently accumulated in the culture medium; indeed, it has been demonstrated that cyanobacteria produce exopolysaccharides that remain in culture medium (Richert et al., 2005). However, the values obtained in this study show that the TC results do not comply with the European Commission Directive 98/15/EEC requirements for the disposal of treated wastewater in sensitive areas (Directive, 1998) since a linear relationship exists between TOC and COD (COD $=7.25+2.99 *$ TOC (Dubber and Gray, 2010)). Therefore, for a total organic carbon concentration of $37.5 \mathrm{mg}_{\mathrm{TOC}} \mathrm{l}^{-1}$, the estimated COD value is 114 $\mathrm{mg}_{\mathrm{COD}} \mathrm{l}^{-1}$. Better results were achieved in tubular PBRs, where a minimal value of $61.4 \mathrm{mg}_{\mathrm{COD}} \cdot 1^{-1}$ was achieved (Romero Villegas et al., 2017), suggesting that PBR design plays an important role not only in carbon depuration, but also in nitrogen and phosphorus depuration.

Regarding the nitrogen content, analyses were carried out both entering the culture medium and the culture broth exiting the raceway PBR (Fig. 7A). The results ranged from $113.02 \mathrm{mg}_{\mathrm{N}} \cdot \mathrm{l}^{-1}$ to $288 \mathrm{mg}_{\mathrm{N}} \cdot \mathrm{l}^{-1}$ at the inlet when $20 \%-50 \%$ centrate was used. It is important to mention that most of the nitrogen was in the form of ammonium, whereas nitrate values were always below $1.0 \mathrm{mg}_{\mathrm{N}-\mathrm{NO} 3} \cdot \mathrm{l}^{-1}$. Consequently, these assays were performed with greater nitrogen amounts than those carried out with commercial alga medium (using nitrate as the nitrogen source) (San Pedro et al., 2015). Nitrogen at the outlet (Fig. 7A) showed a maximal depuration capacity (Fig. 7B) of up to $90 \%$ $\left(23.38 \mathrm{mg}_{\mathrm{N}}\right.$ day $^{-1}$ ) with $20 \%$ centrate for both dilution rates. Nevertheless, the maximal removal capacity (Fig. 7B) was reached when $50 \%$ centrate was used $\left(65.46 \mathrm{mg}_{\mathrm{N}} \mathrm{l}^{-1} \cdot \mathrm{day}^{-1}\right)$, which demonstrates that nitrogen was not only consumed by the microalgae, but it was also released to the air by stripping, showing ranges from $21.32 \%$ to $73.13 \%$. However, the final content of total nitrogen at the outlet faucet did not comply with European Commission Directive 98/15/EEC for the disposal of urban wastewater with a nitrogen content (a maximum of $10 \mathrm{mg}_{\mathrm{N}} \mathrm{l}^{-1}$ ) to sensitive areas (Directive, 1998) under any set conditions. Previous studies showed that a nitrogen concentration above $100 \mathrm{mg}_{\mathrm{N}-\mathrm{NH} 4} \cdot \mathrm{l}^{-1}$ is toxic for some microalgae strains (Lincoln et al., 1996); although many others exist that can tolerate up to $700 \mathrm{mg}_{\mathrm{N}}$ $\mathrm{NH}_{4} \cdot 1^{-1}$ (Collos et al., 2005). Because this pool of microalgae was native to the centrate used, it could tolerate up to $280 \mathrm{mg}_{\mathrm{N}-\mathrm{NH} 4}$; thus, making the process more sustainable. Analogous works carried out on tubular PBRs (Romero Villegas et al., 2017) showed that, even though raceways had a better nitrogen-consuming efficiency than flat-panels (RomeroVillegas et al., 2018), they were not as efficient as tubular PBRs. This might be explained because closed systems have more effective microalgal production, and consequently, consume more nitrogen (Tredici and Zlttelli, 1998). Vertical flat-panel PBRs, on the other hand, have poorer gas transfer and light-utilization efficiency than do closed systems (Carvalho et al., 2006), which makes nutrient up-take more difficult. Furthermore, raceway PBRs have greater air surface contact, allowing more gas exchange to the air, so more nitrogen is released to the atmosphere.

Regarding phosphorus (Fig. 7C; 7D), it is important to mention, first at all, that phosphorus was added to the culture medium to achieve a $\mathrm{N}: \mathrm{P}$ ratio of $5: 1$, since it has been demonstrated that an imbalanced $\mathrm{N}: \mathrm{P}$ ratio (an insufficient phosphorus content) negatively affects culture performance (Ledda et al., 2015; Sepúlveda et al., 2015). Our results showed that, as a function of the increased centrate in the culture medium, phosphorus at the inlet (Fig. 7C) showed a similar pattern to that for nitrogen, with values from $16 \mathrm{mg}_{\mathrm{p}} \cdot \mathrm{1}^{-1}-45.82 \mathrm{mg}_{\mathrm{p}} \cdot \mathrm{1}^{-1}$; whereas at the outlet, minimal values $\left(3.2 \mathrm{mg}_{\mathrm{p}} \cdot 1^{-1}\right)$ were achieved with $20 \%$ centrate and a dilution rate of $0.3 \mathrm{day}^{-1}$. On the other hand, phosphorus depuration efficiency (Fig. 7D) averaged 82\% for whichever parameters set, and a maximal removal capacity (Fig. 7D) of 11.11 $\mathrm{mg}_{\mathrm{p}} \cdot \mathrm{l}^{-1} \cdot \mathrm{day}^{-1}$ when $50 \%$ centrate was used. In analogous works, the minimal phosphorus values were $0.17 \mathrm{mg}_{\mathrm{p}} \cdot 1^{-1}$ in tubular PBRs (Romero Villegas et al., 2017), whereas in our work, the phosphorus consumption was insufficient, showing minimal values of $3.6 \mathrm{mg}_{\mathrm{p}} \cdot \mathrm{1}^{-1}$ and 3.2 $\mathrm{mg}_{\mathrm{p}} \cdot \mathrm{l}^{-1}$ for dilution rates of 0.2 day $^{-1}$ and 0.3 day $^{-1}$, respectively, when $20 \%$ centrate was used; this rose as the centrate percentage increased in the culture medium.

The study of marine microalgae strains, cultivated using centrate as the sole nutrient source, which permits the removal of compounds such as nitrogen and phosphorus, has grabbed the world's attention because of the potential reduction in freshwater wastage and avoidance of the higher costs involved when using fertilizers. A previous work demonstrated the capacity of a freshwater microalgae bloom, comprising 7 microalgae strains, to depurate up to $80 \%$ of the total nitrogen and total phosphorus from urban wastewaters (Mennaa et al., 2015). Similarly, a freshwater microalgae monoculture (Scenedesmus sp.) was able to depurate up to $55 \%$ of the nitrogen and $10 \%$ of the phosphorus, with inlet values of $240 \mathrm{mg}_{\mathrm{N}} \cdot \mathrm{l}^{-1}$ and $42 \mathrm{mg}_{\mathrm{P}} \cdot \mathrm{l}-1$ using centrate as the culture medium in raceway PBRs (Morales-Amaral et al., 2015). Moreover, studies carried out under indoor/outdoor conditions on Nannochloropsis g., using centrate as the culture medium, showed it was possible to depurate up to $80 / 64 \%$ of the nitrogen, and $86 / 94 \%$ of the phosphorus, respectively (Ledda et al., 2015; Sepúlveda et al., 2015). However, in this work, neither the nitrogen results nor the phosphorus results complied with European Commission Directive 98/15/EEC requirements for the disposal of treated wastewater in sensitive areas (Directive, 1998), which imposes maximums of $10 \mathrm{mg}_{\mathrm{N}} \mathrm{l}^{-1}$ and 2 $\mathrm{mg}_{\mathrm{p}} \cdot 1^{-1}$.

For the large-scale use of centrate as the culture medium along with flue gases, it has been shown that production cost can be reduced from $2.3 € \cdot \mathrm{kg}^{-1}$ to $1.8 € \mathrm{~kg}^{-1}$ using raceways PBRs (Morales-Amaral et al., 2015) whereas for tubular and flat-panel PBRs, it can be reduced to 2.1 $€ \cdot \mathrm{kg}^{-1}$ (Acién et al., 2012) and $4 € \cdot \mathrm{kg}^{-1}$ (Wijffels et al., 2010), respectively. Moreover, native microalgae have proved capable of depurating up to $99 \%$ of the carbon compounds found in urban wastewater using raceway PBRs (Matamoros et al., 2015). In addition, it has been proven that a carbon source maximizes microalgal growth (Liu et al., 2009) unlike $\mathrm{CO}_{2}$; this can explain the difference between the biomass concentration obtained with commercial algal medium, where a maximal biomass concentration of $0.41 \mathrm{~g}_{\text {biomass }} \mathrm{l}^{-1}$ was obtained (San Pedro et al., 2015).

\subsection{Nutrient mass balance}

As well as demonstrating that compounds such as carbon, nitrogen and phosphorus can be depurated in this type of low-cost technology, it is also important to understand the microalgal phenomena occurring in the wastewater depuration system. This is because there are certain phenomena, such as stripping and sedimentation, which participate in the depuration process alongside biomass fixation. Mass balance (Fig. 8) can be used to evaluate the phenomena occurring during wastewater depuration. Regarding the carbon mass balance (Fig. 8A), it was shown that, in all the cases, the carbon content in the culture medium was insufficient to satisfy the microalgae bloom's carbon demand; for this reason, it was supplemented with up to $53 \%$ carbon using $\mathrm{CO}_{2}$ from flue gas (data not shown). It was also evidenced that more than $60 \%$ of total carbon was fixed into biomass, under whichever conditions set, apart from at $50 \%$ centrate. Nevertheless, the most effective treatment for removing carbon used $20 \%$ centrate, which utilised $80 \%$ of the total carbon. However, there is an opposite effect, carbon "loss" - this diminished as centrate increased in the culture medium, ranging from 7.6 to $5 \%$, even when $50 \%$ centrate was used. 

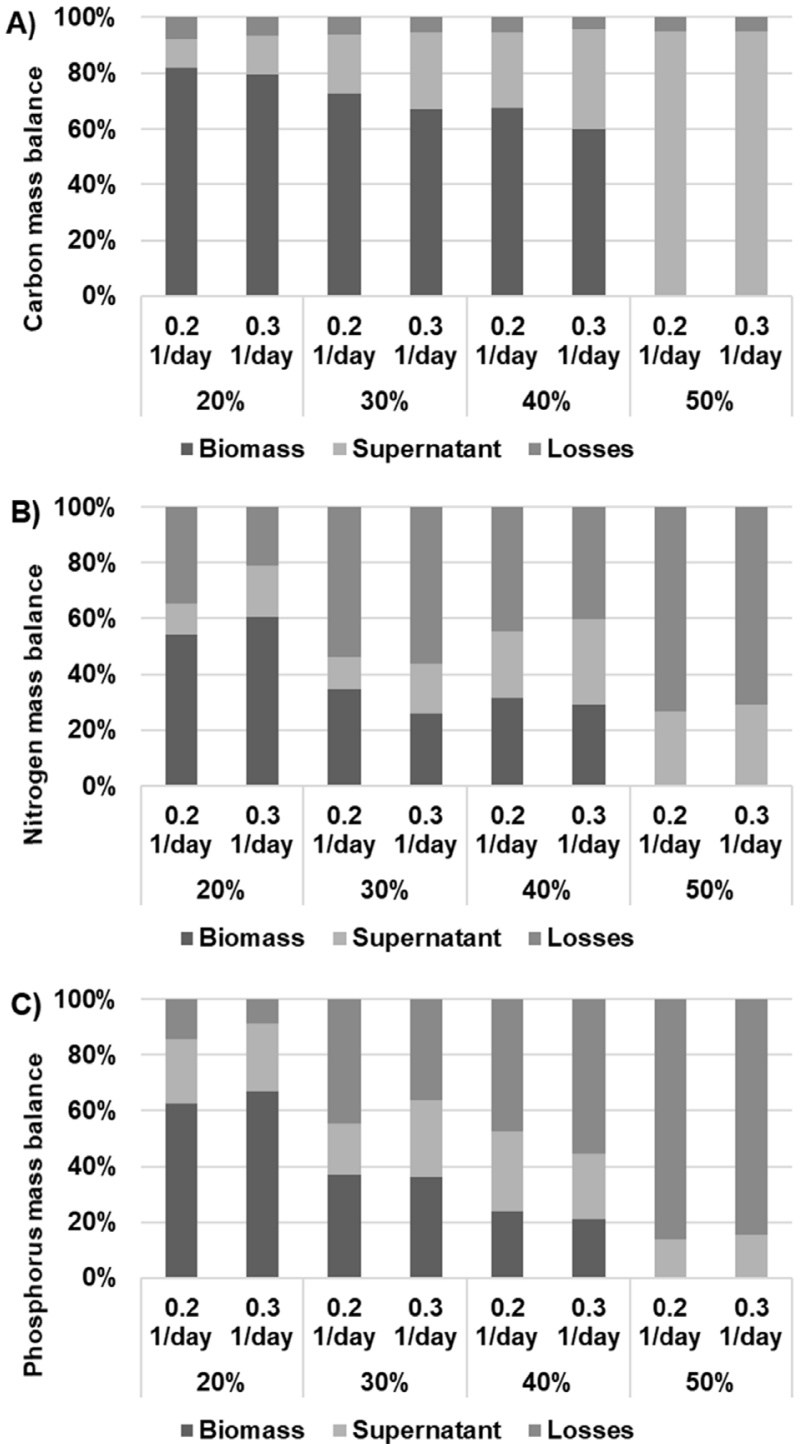

Fig. 8. Influence of the centrate percentage in the culture medium and the imposed dilution rate on the carbon, nitrogen and phosphorus mass balance of the system in the outdoor raceway photobioreactors. A) Carbon mass balance, B) Nitrogen mass balance, C) Phosphorus mass balance. Mean + S.D. values are shown for the independent experiments performed in triplicate $(\mathrm{P}<0.05)$.

Furthermore, the results (Fig. 6) demonstrated that TOC increased along with centrate, confirming that microalgae produced exopolysaccharides (Khattar et al., 2010) reduced, like biomass productivity did, as centrate in the culture medium increased. This agrees with analogous studies on tubular PBRs, where the carbon loss trend followed the same behaviour, with values ranging from 9 to $15 \%$ (Romero Villegas et al., 2017).

Regarding the nitrogen mass balance, the results confirms what has already been stated concerning ammonium toxicity. Fig. 8B, shows a maximal nitrogen fixation of $60.61 \%$ when $20 \%$ centrate and a dilution rate of 0.3 day $^{-1}$ were used. In addition, it shows that nitrogen fixation reduced as the centrate percentage increased. On the other hand, a certain percentage of total nitrogen remained in the culture medium, increasing as centrate increased, exhibiting values from $22 \%$ to $30 \%$. The data also show that the stripping phenomenon was present in the system, presenting nitrogen loss values of $21.32 \%$ in the best case, whereas the maximum nitrogen loss from stripping was observed at $50 \%$ centrate, with values up to $73 \%$. It is important to note that no nitrification was detected and, as a consequence, the increased ammonium/ammonia in the culture medium led to an increase in the driving force for nitrogen stripping. Previous studies demonstrated that a combination of $\mathrm{pH}>9.5$, a temperature of $70^{\circ} \mathrm{C}$ and a continuous airflow of $15001 \mathrm{~min}^{-1}$ can depurate up to $92 \%$ of total ammonium, with initial values of up to $2200 \mathrm{mg}_{\mathrm{N}-\mathrm{NH} 3} \cdot \mathrm{l}^{-1}$ (Guštin and MarinšekLogar, 2011); whereas Liao et al. (1995) showed the best results when the temperature, $\mathrm{pH}$ and air flow were set at $22^{\circ} \mathrm{C}, 9.5$ and $401 \mathrm{~min}^{-1}$, respectively, showing that stripping is an efficient technique for depurating wastewaters. Taking all this into account, our results confirm that a mix of these factors along with good microalgae bloom performance can provide acceptable nitrogen depuration. Similar behaviour was observed in tubular PBRs, where nitrogen fixation was the main phenomenon occurring in the culture, representing up to $74 \%$ of nitrogen depuration (Romero Villegas et al., 2017).

With regard to the phosphorus mass balance (Fig. 8C), the data show a similar trend to that obtained for nitrogen, in which the fixed phosphorus concentration diminished as centrate increased in the culture medium. The data presented a decreasing trend from $67 \%$ to $21 \%$ as the centrate percentage rose from $20 \%$ to $40 \%$; however, the values fell to zero for $50 \%$ centrate. Additionally, it was evidenced that the phosphorus remaining in the culture medium was very stable at an average of $24 \%$. Nevertheless, as with nitrogen, the data indicate that phosphorus was being lost, presenting values from $9 \%$ to $86 \%$ as centrate increased. Similar results were observed in tubular PBRs, where phosphorus losses rose with increased centrate in the culture medium, reaching values of $76 \%$ (Romero Villegas et al., 2017). Nevertheless, the most similar results were those obtained in tubular PBRs, suggesting that horizontal surfaces, such as those found in tubular and raceway PBRs, allow phosphate precipitation; while flat-panel PBRs generate a constant and circular flow current that is always mixing the culture, thus inhibiting salt precipitation. It has been demonstrated that phosphate precipitates as a function of alkaline $\mathrm{pH}$ and temperatures above $20^{\circ} \mathrm{C}$ (Burns et al., 2003).

\section{Conclusions}

In this paper, the importance of nutrient recycling is demonstrated as well as using microalgal consortia for wastewater depuration and biomass production. In addition, it was shown that centrate can be used as the sole nutrient source for marine microalgae in outdoor raceway PBRs. Moreover, the relative population in the PBRs can be changed by modifying the centrate percentage in the culture medium; whereas it barely changes at all when modifying the dilution rate. Furthermore, the biochemical composition analysis allowed us to assess the biomass obtained for its final application, which could be as a feed product. Despite the final nitrogen, phosphorus and carbon values not complying to those limits required by law, the culture medium could be recirculated to achieve the low nutrient content necessary for its final disposal. The set of works considered in this study have helped to identify the main phenomena occurring when centrate is used as a nutrient source to produce marine microalgae strains, making centrate utilization a promising strategy for producing sustainable and profitable microalgal biomass for low-cost applications.

\section{Acknowledgements}

This research was supported by the EDARSOL Project (CTQ201457293-C3) financed by the Spanish Government and Junta de Andalucia (BIO 173). Gabriel Ivan Romero Villegas and Marco Fiamengo's contributions were financially supported by the Consejo Nacional de Ciencia y Tecnología (CONACyT, México) and by the Erasmus + traineeship programme of the Università di Ferrara.

\section{References}

Acién, F.G., Fernández, J.M., Magán, J.J., Molina, E., 2012. Production cost of a real 
microalgae production plant and strategies to reduce it. Biotechnol. Adv. 30, 1344-1353. https://doi.org/10.1016/j.biotechadv.2012.02.005.

Acién, F.G., Fernández, J.M., Molina-Grima, E., 2014. Economics of microalgae biomass production. In: Biofuels from Algae. Elsevier, pp. 313-325. https://doi.org/10.1016/ B978-0-444-59558-4.00014-0.

Aksu, Z., Kutsal, T., 1991. A bioseparation process for removing lead(II) ions from waste water by using C. vulgaris. J. Chem. Technol. Biotechnol. 52, 109-118. https://doi. org/10.1002/jctb.280520108.

APAT-IRSA/CNR, 2003. Metodologie analitiche per il controllo della qualità delle acque [Analytical methodologies for water quality management], vol. 29. Poligr. e Zecca dello Stato, Roma, Ital., pp. 575-581.

Bagus Pradana, A., Buchori, L., Sri Budiyati, C., 2014. Biosorption of heavy metal Cu $2+$ and $\mathrm{Cr} 2+$ in textile wastewater by using immobilized algae. Res. J. Appl. Sci. Eng, Technol. 7, 3539-3543.

Burns, R.T., Moody, L.B., Celen, I., Buchanan, J.R., 2003. Optimization of phosphorus precipitation from swine manure slurries to enhance recovery. In: Water Science and Technology, pp. 139-146.

Carvalho, A.P., Meireles, L.A., Malcata, F.X., 2006. Microalgal reactors: a review of enclosed system designs and performances. Biotechnol. Prog. https://doi.org/10.1021/ bp060065r.

Chisti, Y., 2008. Biodiesel from microalgae beats bioethanol. Trends Biotechnol. 26, 126-131.

Collos, Y., Vaquer, A., Souchu, P., 2005. Acclimation of nitrate uptake by phytoplankton to high substrate leves s1. J. Phycol. 41, 466-478. https://doi.org/10.1111/j.15298817.2005.00067.x.

Craggs, R.J., McAuley, P.J., Smith, V.J., 1997. Wastewater nutrient removal by marine microalgae grown on a corrugated raceway. Water Res. 31, 1701-1707. https://doi. org/10.1016/S0043-1354(96)00093-0.

Directive, E.C., 1998. Commission Directive 98/15/EC.

Dubber, D., Gray, N.F., 2010. Replacement of chemical oxygen demand (COD) with total organic carbon (TOC) for monitoring wastewater treatment performance to minimize disposal of toxic analytical waste. J. Environ. Sci. Heal. 45 (Part A), 1595-1600. https://doi.org/10.1080/10934529.2010.506116.

Edler, L., Elbrächter, M., 2010. The Utermöhl method for quantitative phytoplankton analysis. Microsc. Mol. methods Quant. Phytoplankt. Anal. 13-20. https://doi.org/ 10.1016/j.resp.2011.02.009.

Guštin, S., Marinšek-Logar, R., 2011. Effect of pH, temperature and air flow rate on the continuous ammonia stripping of the anaerobic digestion effluent. Process Saf. Environ. Protect. 89, 61-66. https://doi.org/10.1016/j.psep.2010.11.001.

Hanifzadeh, M., Sarrafzadeh, M.-H., Nabati, Z., Tavakoli, O., Feyzizarnagh, H., 2018. Technical, economic and energy assessment of an alternative strategy for mass production of biomass and lipid from microalgae. J. Environ. Chem. Eng. 6, 866-873. https://doi.org/10.1016/j.jece.2018.01.008.

Henley, E.J., Seader, J.D., Roper, D.K., 2011. Separation Process Principles. Wiley, New York.

Imani, S., Rezaei-Zarchi, S., Hashemi, M., Borna, H., Javid, a, Zand, a M., Abarghouei, H.B., 2011. Hg, Cd and Pb heavy metal bioremediation by Dunaliella alga. J. Med. Plants Res. 5, 2775-2780.

Jiang, L., Luo, S., Fan, X., Yang, Z., Guo, R., 2011. Biomass and lipid production of marine microalgae using municipal wastewater and high concentration of CO 2. Appl. Energy 88, 3336-3341. https://doi.org/10.1016/j.apenergy.2011.03.043.

Khattar, J.I.S., Singh, D.P., Jindal, N., Kaur, N., Singh, Y., Rahi, P., Gulati, A., 2010 Isolation and characterization of exopolysaccharides produced by the cyanobacterium Limnothrix redekei PUPCCC 116. Appl. Biochem. Biotechnol. 162, 1327-1338.

Ledda, C., Romero-Villegas, G.I., Adani, F., Acién-Fernández, F.G., Molina-Grima, E., 2015. Utilization of centrate from wastewater treatment for the outdoor production of Nannochloropsis gaditana biomass at pilot-scale. Algal Res. 12. https://doi.org/ 10.1016/j.algal.2015.08.002

Ledda, C., Schievano, A., Scaglia, B., Rossoni, M., Acién Fernández, F.G., Adani, F., 2016. Integration of microalgae production with anaerobic digestion of dairy cattle manure: an overall mass and energy balance of the process. J. Clean. Prod. 112, 103-112. https://doi.org/10.1016/j.jclepro.2015.07.151.

Liao, P.H., Chen, A., Lo, K.V., 1995. Removal of nitrogen from swine manure wastewaters by ammonia stripping. Bioresour. Technol. 54, 17-20. https://doi.org/10.1016/ 0960-8524(95)00105-0.

Lincoln, E.P., Wilkie, A.C., French, B.T., 1996. Cyanobacterial process for renovating dairy wastewater. Biomass Bioenergy 10, 63-68. https://doi.org/10.1016/0961 9534(95)00055-0.

Liu, X.J., Duan, S.S., Li, A.F., Xu, N., Cai, Z.P., Hu, Z.X., 2009. Effects of organic carbon sources on growth, photosynthesis, and respiration of Phaeodactylum tricornutum. J. Appl. Phycol. 21, 239-246. https://doi.org/10.1007/s10811-008-9355-z.

López González, C.V., Cerón García, M. del C., Acién Fernández, F.G., Segovia Bustos, C., Chisti, Y., Fernández Sevilla, J.M., 2010. Protein measurements of microalgal and cyanobacterial biomass. Bioresour. Technol. 101, 7587-7591. https://doi.org/10. 1016/j.biortech.2010.04.077.

Maizatul, A.Y., Radin Mohamed, R.M.S., Al-Gheethi, A.A., Hashim, M.K.A., 2017. An overview of the utilisation of microalgae biomass derived from nutrient recycling of wet market wastewater and slaughterhouse wastewater. Int. Aquat. Res. https://doi. org/10.1007/s40071-017-0168-Z.

Matamoros, V., Gutiérrez, R., Ferrer, I., García, J., Bayona, J.M., 2015. Capability of microalgae-based wastewater treatment systems to remove emerging organic contaminants: a pilot-scale study. J. Hazard. Mater. 288, 34-42. https://doi.org/10. 1016/j.jhazmat.2015.02.002.

Mennaa, F.Z., Arbib, Z., Perales, J.A., 2015. Urban wastewater treatment by seven species of microalgae and an algal bloom: biomass production, $\mathrm{N}$ and $\mathrm{P}$ removal kinetics and harvestability. Water Res. 83, 42-51. https://doi.org/10.1016/j.watres.2015.06.007.

Ministerio de Agricultura, P. y A., 1998. Métodos oficiales de análisis de la Unión Europea, vol. 2 Métodos oficiales de análisis. Ministerio de Ministerio de Agricultura, Pesca y Alimentación, Secretaría General Técnica, Madrid, España.

Molina Grima, E., Fernández Sevilla, J.M., Sánchez Pérez, J.A., García Camacho, F., 1996. A study on simultaneous photolimitation and photoinhibition in dense microalgal cultures taking into account incident and averaged irradiances. J. Biotechnol. 45, 59-69. https://doi.org/10.1016/0168-1656(95)00144-1.

Morales-Amaral, M. del M., Gómez-Serrano, C., Acién, F.G., Fernéndez-Sevilla, J.M. Molina-Grima, E., 2015. Outdoor production of Scenedesmus sp. in thin-layer and raceway reactors using centrate from anaerobic digestion as the sole nutrient source. Algal Res. 12, 99-108. https://doi.org/10.1016/j.algal.2015.08.020.

Norsker, N.H., Barbosa, M.J., Vermuë, M.H., Wijffels, R.H., 2011. Microalgal production a close look at the economics. Biotechnol. Adv. https://doi.org/10.1016/j. biotechadv.2010.08.005.

Posadas, E., del Mar Morales, M., Gomez, C., Acién, F.G., Muñoz, R., 2015. Influence of $\mathrm{pH}$ and $\mathrm{CO} 2$ source on the performance of microalgae-based secondary domestic wastewater treatment in outdoors pilot raceways. Chem. Eng. J. 265, 239-248.

Raven, J., 1979. Handbook of Phycological Methods: Physiological and Biochemical Methods: Phytochemistry, vol. 18. pp. 1422-1423. https://doi.org/10.1016/0031 9422(79)83048-4.

Richert, L., Golubic, S., Guédès, R. Le, Ratiskol, J., Payri, C., Guezennec, J., 2005. Characterization of exopolysaccharides produced by cyanobacteria isolated from polynesian microbial mats. Curr. Microbiol. 51, 379-384. https://doi.org/10.1007/ s00284-005-0069-z.

Rodríguez-Ruiz, J., Belarbi, E.H., Sánchez, J.L.G., Alonso, D.L., 1998. Rapid simultaneous lipid extraction and transesterification for fatty acid analyses. Biotechnol. Tech. 12, 689-691. https://doi.org/10.1023/A:1008812904017.

Romero Villegas, G.I., Fiamengo, M., Acien-Fernández, F.G., Molina-Grima, E., 2017. Outdoor production of microalgae biomass at pilot-scale in seawater using centrate as the nutrient source. Algal Res. 25, 1-11. https://doi.org/10.1016/j.algal.2017.06. 016.

Romero-Villegas, G.I., Fiamengo, M., Acién Fernández, F.G., Molina Grima, E., 2018. Utilization of centrate for the outdoor production of marine microalgae at pilot-scale in flat-panel photobioreactors. J. Biotechnol. 284, 102-114. https://doi.org/10. 1016/j.jbiotec.2018.08.006

Ruiz, J., Olivieri, G., de Vree, J., Bosma, R., Willems, P., Reith, J.H., Eppink, M.H.M., Kleinegris, D.M.M., Wijffels, R.H., Barbosa, M.J., 2016. Towards industrial products from microalgae. Energy Environ. Sci. 24, 405-413. https://doi.org/10.1039/ C6EE01493C.

San Pedro, A., González-López, C.V., Acién, F.G., Molina-Grima, E., 2014. Outdoor pilotscale production of Nannochloropsis gaditana: Influence of culture parameters and lipid production rates in tubular photobioreactors. Bioresour. Technol. 169, 667-676. https://doi.org/10.1016/j.biortech.2014.07.052.

San Pedro, A., González-López, C.V., Acién, F.G., Molina-Grima, E., 2015. Outdoor pilot production of Nannochloropsis gaditana: Influence of culture parameters and lipid production rates in raceway ponds. Algal Res. 18, 205-213. https://doi.org/10.1016/ j.algal.2015.02.013.

Sepúlveda, C., Acién, F.G., Gómez, C., Jiménez-Ruíz, N., Riquelme, C., Molina-Grima, E., 2015. Utilization of centrate for the production of the marine microalgae Nannochloropsis gaditana. Algal Res. 9, 107-116. https://doi.org/10.1016/j.algal. 2015.03.004.

Slade, R., Bauen, A., 2013. Micro-algae cultivation for biofuels: cost, energy balance, environmental impacts and future prospects. Biomass Bioenergy 53, 29-38. https:// doi.org/10.1016/j.biombioe.2012.12.019.

Soley Biotechnology Institute, 2014. High Quality \%100 Organic Soil Fertilizers by Microalgae Mixture [WWW Document]. http://www.algaeinstitute.com/products/ organic-fertilizer.html\#sthash.BDtJle1n.dpuf.

Terry, P.A., Stone, W., 2002. Biosorption of cadmium and copper contaminated water by Scenedesmus abundans. Chemosphere 47, 249-255. https://doi.org/10.1016/S00456535(01)00303-4.

Transparency Market Research, 2014. Biofertilizers Market - Global Industry Analysis, Size, Share, Growth, Trends and Forecast. pp. 2013-2019.

Tredici, M.R., Zlttelli, G.C., 1998. Efficiency of sunlight utilization: tubular versus flat photobioreactors. Biotechnol. Bioeng. 57, 187-197. https://doi.org/10.1002/(SICI) 1097-0290(19980120)57:2<187::AID-BIT7 > 3.0.CO;2-J.

Ugwu, C.U., Aoyagi, H., Uchiyama, H., 2008. Photobioreactors for mass cultivation of algae. Bioresour. Technol. https://doi.org/10.1016/j.biortech.2007.01.046.

Van Harmelen, T., Oonk, H., 2006. Microalgae Biofixation Processes: Applications and Potential Contributions to Greenhouse Gas Mitigation Options. TNO Built Environment and Geosciences, Apeldoorn, The Netherlands. The Netherlands.

Wijffels, R.H., Barbosa, M.J., Eppink, M.H.M., 2010. Microalgae for the production of bulk chemicals and biofuels. Biofuels, Bioprod. Biorefining 4, 287-295. https://doi. org/10.1002/bbb/215.

Yang, J., Xu, M., Zhang, X., Hu, Q., Sommerfeld, M., Chen, Y., 2011. Life-cycle analysis on biodiesel production from microalgae: water footprint and nutrients balance. Bioresour. Technol. 102, 159-165. 